\title{
O PROCESSO DE ENSINO APRENDIZAGEM DA EDUCAÇÃO AMBIENTAL
}

\author{
Karine Bueno Vargas ${ }^{1}$
}

\begin{abstract}
RESUMO
Neste artigo é discutido o papel da disciplina educação ambiental no ensino superior com o objetivo de tentar perceber nos conteúdos e na grade curricular das instituições e cursos que possuem esta disciplina ou abordam o tema, certas preocupações com a mudança no comportamento dos alunos frente aos cuidados com o meio ambiente. Como metodologia, foi utilizada a analítica descritiva e levantamento bibliográfico, verificando o avanço da conscientização ambiental nos alunos pelo uso da práxis pelos docentes no processo de ensino aprendizagem, ao longo das disciplinas de educação ambiental ou pela interdisciplinaridade de disciplinas da área das ciências ambientais que abordam a temática. Identificamos que a aplicação da teoria e da prática no ensino aprendizagem da educação ambiental tem potencial para fazer os alunos repensarem seu modo de ser e agir.
\end{abstract}

PALAVRAS-CHAVE: Práxis, Educação Ambiental, Ensino Aprendizagem.

\section{THE PROCESS OF LEARNING TEACHING ENVIRONMENTAL EDUCATION}

\begin{abstract}
This paper aims to discuss the role of discipline environmental education in higher education, aiming to recognize the content and curriculum of courses and institutions that have the discipline or address the issue to change the behavior of students in relation to the care of the environment. The methodology used was the descriptive analytical and lifting bibliographic, checking the progress of environmental awareness in students by the use of practice by teachers in the learning process throughout the disciplines of environmental education or the interdisciplinarity of disciplines of the environmental sciences which deal the thematic. Identified that application of theory and practice in the teaching and learning of environmental education has the potential to get students to rethink their way of being and acting.
\end{abstract}

KEY-WORDS: Praxis, Environmental Education, Teaching Learning.

\section{EL PROCESO DE APRENDIZAJE DE ENSEÑANZA DE EDUCACIÓN AMBIENTAL}

\section{RESUMEN}

En este artículo se analiza el papel de la educación ambiental disciplina en la educación superior con el fin de tratar de entender el contenido y el plan de estudios de las instituciones y cursos que tienen esta disciplina o abordan el tema, algunas preocupaciones sobre el cambio en el comportamiento de

\footnotetext{
${ }^{1}$ Doutoranda em Geografia, Universidade Estadual de Maringá. E-mail: karibvargas@yahoo.com.br
} 
los estudiantes frente al cuidado del medio ambiente. La metodología utilizada fue un análisis descriptivo y literatura, comprobar el progreso de la conciencia ambiental en los estudiantes al utilizar la práctica por los profesores en la enseñanza aprendizaje, ao longo das disciplinas de educação ambiental ou pela interdisciplinaridade de disciplinas da área das ciências ambientais que abordam a temática. Se encontró que la aplicación de la teoría y la práctica en la enseñanza y el aprendizaje de la educación ambiental tiene el potencial de hacer que los estudiantes repensar su forma de ser y de actuar.

PALABRAS-CLAVE: Practica, Educación Ambiental, Educación Aprendizaje.

\section{INTRODUÇÃO}

O homem, ao longo de sua história, utilizou os recursos naturais de forma irracional para atender a suas próprias necessidades, iniciou as mudanças no ambiente com o desenvolvimento da agricultura e posteriormente com o processo de industrialização. No entanto, com o passar dos anos foi verificando algumas problemáticas no ambiente, e foi percebendo que tais alterações eram oriundas da maneira como ele se apropriava do espaço. A partir disso, alguns homens começaram a repensar suas atitudes.

Segundo Nascimento (2012), a partir da década de 70, crescem as manifestações ambientais cujo objetivo era preservar e proteger. Os movimentos que aconteceram nessa década são considerados os primeiros realizados com grandes massas populacionais, mostrando o envolvimento de uma sociedade um pouco mais consciente do seu papel na busca por melhores condições de vida.

Nessa época, entretanto, os modelos educacionais vigentes eram rígidos e, por muitas vezes, distantes da realidade do povo. Seria preciso criar um "novo" processo educacional, que fosse capaz de promover as mudanças necessárias. Surge, então, a "educação ambiental", com a finalidade de promover a compreensão das relações políticas, sociais e ecológicas da sociedade e induzir novas formas de conduta nos indivíduos e nos grupos sociais, na busca de soluções para os problemas ambientais e para a melhoria da qualidade de vida.

Para a Organização das Nações Unidas, a educação ambiental é vista como um processo permanente no qual os indivíduos e a comunidade tomam consciência do seu meio ambiente e adquirem conhecimentos, habilidades, experiências, valores e a determinação que os tornam capazes de agir, individual ou coletivamente, na busca de soluções para os problemas ambientais, presentes e futuros. 
O aprofundamento da educação ambiental deve ser baseado em um modelo ético de conhecimento e com a participação ativa e permanente da sociedade, onde cada ser que atua no meio ambiente possa tratá-lo com respeito e viver de uma maneira mais harmoniosa, gerando possibilidades de as gerações futuras poderem usufruir dos recursos naturais existentes até o momento.

Nesse sentido, o presente artigo faz uma releitura sobre a temática educação ambiental, tendo como objetivo refletir sobre a influência da práxis no ensino aprendizagem desta disciplina ou em disciplinas que abordam a temática no ensino superior. Foi analisado os conteúdos das ementas e sua relevância, verificando se sua aplicação em sala de aula vem a refletir na conversão de atitudes dos alunos e como esse conhecimento vem sendo reproduzido no cotidiano, já que uma de suas metas é "ensinar para refletir sobre a realidade". No entanto, é importante deixar claro que a educação ambiental não é um processo mágico, ela é um processo contínuo de aprendizagem e exercício da cidadania, necessitando ter uma visão crítica da realidade e uma atuação mais consciente do espaço social.

A metodologia apoia-se na análise analítica descritiva, observando como os aluno tem compreendido a necessidade de cuidar melhor do espaço de vivência, estendendo-se para outras áreas de circulação e permanência, verificando como os alunos chegam e como saem após o contato com disciplinas que trabalham com Educação Ambiental.

\section{METODOLOGIA}

$\mathrm{O}$ artigo tem por finalidade analisar e refletir sobre o ensino-aprendizagem e a organização curricular do ensino superior da disciplina de educação ambiental e de outras disciplinas que abordam a temática. Diante disso, o trabalho iniciou-se com revisão bibliográfica acerca da temática, identificando a importância da utilização da teoria e prática no ensino de educação ambiental. A pesquisa seguiu a metodologia analítica descritiva, considerando a vivencia docente no ensino superior sobre a observação dos alunos, frente a suas posturas com relação ao meio ambiente no decorrer do desenvolvimento das disciplinas e o seu envolvimento com estas. 
A disciplina de educação ambiental, independente do seu local de aplicação, tem como objetivo não apenas ensinar, mas educar para uma vida, para que o aluno conscientize-se e respeite a natureza. Seguindo os preceitos de Troppmair (2002, p.171) "conservar a natureza não significa não tocá-la, mas sim, utilizá-la de forma racional respeitando os parâmetros ecológicos de recomposição, de equilíbrio, de harmonia" em que esta se encontra reconhecendo-se neste ambiente, já que, de acordo com o mesmo autor, "a base da educação ambiental reside no envolvimento e participação" se tornando capaz de discutir problemas e resolvê-los.

\section{RESULTADOS E DISCUSSÕES}

A degradação ambiental, em nível mundial, tem introduzido novos debates à necessidade de uma mudança de mentalidade, de busca de novos valores e em uma nova ética regulamentadora (BUARQUE, 1990). De acordo com Gleiser (1997) o interesse por questões globais e pelo cosmos está atraindo muito mais do que os físicos de hoje, e não só os cientistas, mas o grande público em busca de informações sobre o homem, e sobre o Planeta Terra.

A abordagem ambientalista entrou no século XXI com grande impulso e força, o que de uma maneira geral colocou a temática em destaque na sociedade. Termos como educação ambiental e sustentabilidade têm estado cada vez mais presente na mídia e nos próprios documentos educacionais, no entanto, muitas pessoas nem sabem o valor que está agregado a estas palavras.

A falta de conhecimento acerca de temas relacionados a meio ambiente $e$ Educação Ambiental, sobretudo com pessoas com mais de 40 anos de idade, é reflexo da falta de abordagem do tema durante a escolarização destes, já que a discussão ambiental é relativamente recente no ensino. O conceito de educação ambiental é contextualizado em 1972, na Conferência de Estocolmo, mas somente em meados da década de 1990 que entra no discurso escolar, ganhando maior destaque no Brasil com a realização da Conferência das Nações Unidas sobre o Meio Ambiente e Desenvolvimento, em 1992 no Rio de Janeiro, também conhecida como Rio 92. O evento reuniu mais de cem chefes de estado que buscavam meios de conciliar o desenvolvimento socioeconômico com a conservação e proteção de ecossistemas da terra. 
De acordo com Nascimento (2012), o significado da junção das palavras educação e ambiental refletem em um conhecimento relativo ao meio ambiente, ou seja, o saber é o princípio para se ter uma postura de aplicação desses conhecimentos. A autora supracitada ainda ressalta que a educação ambiental é uma ação educativa que forma e informa o cidadão consciente da preservação, que pode tomar decisões individuais e coletivas sobre os questionamentos ambientais rumo a uma sociedade sustentável.

Já os termos meio ambiente e sustentabilidade se referem ao espaço geográfico em que vivemos e a forma que se apropriamos desse espaço. Dessa forma, o conceito de meio ambiente compreende três aspectos, quais sejam: Meio ambiente natural, ou físico, constituído pelo solo, a água, o ar atmosférico, a flora, enfim, pela interação dos seres vivos e seu meio, onde se dá a correlação recíproca entre as espécies e as relações destas com o ambiente físico que ocupam; Meio ambiente artificial, constituído pelo espaço urbano construído; Meio ambiente cultural, integrado pelo patrimônio histórico, artístico, arqueológico, paisagístico, turístico, que, embora artificial, difere do anterior pelo sentido de valor especial que adquiriu ou de que se impregnou (SILVA, 2004, p. 21).

Diante desse conceito, fica evidente que o meio ambiente não se restringe apenas ao espaço natural, mas abrange todo o espaço terrestre que ocupamos, e preservar o meio ambiente não é apenas cuidar do espaço natural e sim de tudo que nos cerca. Dentro da temática meio ambiente surge outro conceito, que é o desenvolvimento sustentável, que segundo Mikhailova (2004), a sua prática melhora a qualidade da vida do homem na Terra ao mesmo tempo em que respeita a capacidade de produção dos ecossistemas nos quais vivemos. A partir desses dos dois conceitos expostos, observa-se a interface da Educação Ambiental com ambos, que é compreender e conhecer nosso espaço de vivência sem prejudicá-lo, sempre de forma renovável.

$\mathrm{Na}$ Carta de Belgrado (1975), organizada pela UNESCO, podemos observar essa ideia mais holística da Educação Ambiental:

Nós necessitamos de uma nova ética global, uma ética que promova atitudes e comportamentos para os indivíduos e sociedades, que sejam consonantes como o lugar da humanidade dentro da biosfera; que reconheça e responda com sensibilidade às complexas e dinâmicas relações entre a humanidade e a natureza, e entre os povos. Mudanças significativas devem ocorrer em todas as nações do mundo, para assegurar 
o tipo de desenvolvimento racional que será orientado por esta nova ideia global - mudanças que serão direcionadas para uma distribuição equitativa dos recursos da Terra e para atender mais às necessidades dos povos (CARTA DE BELGRADO, 1975, p. 1).

O entendimento é que a participação da sociedade deve ser ativa e permanente, o que fica evidenciado na lei no 9.795, de 27 de abril de 1999. Onde em seu $1^{\circ}$ artigo, apresenta educação ambiental como os processos por meio dos quais o indivíduo e a coletividade constroem valores sociais, conhecimentos, habilidades, atitudes e competências voltadas para a conservação do meio ambiente, bem de uso comum do povo, essencial à sadia qualidade de vida e sua sustentabilidade, sendo mais dinâmico e abrangente.

De acordo com Carneiro (2006, pág 17), as relações sociedade-natureza são contextualizadas a partir das analogias orgânica e mecânica ao foco de uma epistemologia ambiental:

Frente à crise civilizatória no mundo ocidental, nessa linha, o paradigma da complexidade fundamenta a superação das ambiguidades do desenvolvimento sustentável em prol de uma apropriada sustentabilidade socioambiental e, possibilitando práticas de Educação Ambiental, criticamente orientadas por uma nova pedagogia do conhecimento, com implicação de novos saberes e construção de novas relações entre pessoas, sociedade e o meio natural, sob uma ética da responsabilidade (CARNEIRO, 2006. p.17).

Para Cunha (2013), os diálogos entre saberes da pedagogia ambiental trazem a preocupação de superar as dicotomias entre teoria e ação na educação ambiental em três campos interligados: No campo epistemológico, no campo metodológico e no campo político. De acordo com a autora, no campo epistemológico coloca-se a necessidade de formação do educador ambiental no intuito de articular as ciências da vida e as ciências do homem, num horizonte interdisciplinar (ou transdisciplinar), como também a ruptura dos padrões da ciência dominante, na qual outras formas de saberes são relegadas ou anuladas pela história, sendo necessário superar, assim, o caráter academicista, disciplinar e auto-referente da ciência moderna, que elege a si própria como forma única e absoluta de conhecimento a medida de todas as coisas, negando ou congelando outras expressões do saber.

A disciplina de educação ambiental não está presente na grade curricular da educação básica e nem na maioria dos cursos do ensino superior. De acordo com os Parâmetros Curriculares Nacionais (1998), a educação ambiental se encaixa nos 
temas transversais, ou seja, todas as disciplinas devem trabalhar com esta temática, porém não é isso ocorre. O que se observa é que docentes de algumas áreas como Geografia e Biologia, acabam por assumir esta temática no ensino básico devido a maior experiência que tiveram durante sua formação e o contato com os diversos temas das ciências da natureza, enquanto professores de outras áreas muitas vezes nem abordam a temática, ou até mesmo desconhecem da sua essência.

Ao trabalhar com educação ambiental os professores devem estar cientes de que é uma disciplina multidisciplinar, portanto não é responsabilidade apenas da disciplina ou da temática abordada, esta deve perpassar pelas séries iniciais, educação básica e universidade. A educação ambiental deve ser um trabalho contínuo, que tem como objetivo transformar a visão e comportamentos, em muitos casos apáticos, que os alunos/cidadãos têm sobre a natureza, podendo defendê-la e positivamente atuar sobre ela, melhorando a qualidade ambiental e de vida de quem ainda pode desfrutar destes benefícios.

No entanto, docentes que não obtiveram em sua formação uma base sólida de conhecimento a cerca da temática ambiental, correm o risco de não abordarem de forma eficaz a educação ambiental, ou até mesmo, por falta de conhecimento não fazerem a abordagem interdisciplinar, gerando um problema na sala de aula, nas instituições e na sociedade.

Mas um dos desafios é mudar esse cenário, pois se não há uma cobrança por parte de todos os professores com relação a mudanças de atitudes no cotidiano dos alunos, o resultado acaba não sendo tão satisfatório, pois a educação ambiental exige um esforço e uma cobrança constante, já que alguns hábitos como jogar papel no chão, ou não destinar o lixo referente à sua cor para a reciclagem no recipiente correto, fazem parte da vida de nossos alunos ao longo dos anos e vícios de atitudes ecologicamente incorretas necessitam ser identificadas para assim haver uma cobrança de mudança, não só por parte dos docentes como de toda a classe e também da sociedade.

Para Troppmair (2002, p. 171) "a educação ambiental começa no berço, ou seja, o primeiro passo deve ser dado na infância. Deve-se ensinar a criança a observar a beleza e os segredos da Natureza". Dessa forma, deve-se estimular a criança a observar o espaço ao seu redor, para que com isso aprenda a valorizá-lo. 
Mas sabemos que a introdução da educação ambiental na infância não é uma realidade homogenia, pois vivemos numa sociedade cercada de desigualdades nos mais diversos setores, onde muitas pessoas não tiveram nem a oportunidade de estudar, por isso a aplicação da educação ambiental não deve limitar-se para seu início somente na infância, no entanto, quanto mais se demora para iniciar seus princípios mais demorado é a adequabilidade para novas posturas ambientalmente corretas.

No processo de ensino-aprendizagem da educação ambiental, a aprendizagem está atrelada a uma relação social no tempo e no espaço. Os atores desse processo devem ser todos os cidadãos, toda a sociedade envolvida e não apenas um grupo dentro de um conjunto tão amplo. O primeiro passo na educação ambiental é estimular o aluno e os outros grupos sociais a observarem e fazerem a leitura dos ambientes em que vivem assim os mesmos podem relatar suas vivências individuais e coletivas (NASCIMENTO, 2012).

Sob foco educacional, o paradigma da complexidade não se relaciona apenas ao aprendizado de fatos novos, mas com a desconstrução dos princípios epistemológicos da ciência moderna e a fundação de uma nova pedagogia apropriadora do conhecimento "a partir do ser do mundo e do ser no mundo", envolvendo a construção de novos saberes e de uma nova racionalidade, que permitam às atuais e futuras gerações novas maneiras de se relacionar com o mundo (LEFF, 2001, p. 219).

Para Cunha (2012), um dos principais pontos a destacar é que embora uma nova racionalidade ambiental traga consigo desafios epistemológicos e utópicos, ela traz também uma constelação de conhecimentos e práticas ecoprodutivas inovadoras numa relação recíproca e ativa.

Nesse sentido a aplicação da educação ambiental de uma forma moderna e racional vem à práxis, tentando unir o conhecimento por meio a uma prática diária de preservação e conscientização ambiental. De acordo com Godotti (2012), a pedagogia da práxis pretende ser uma educação transformadora, radicando a antropologia que considera o homem um ser incompleto, inconcluso e inacabado e, por isso, um ser criador, sujeito da história, que se transforma na mesma medida em que transforma o mundo. 
O saber ambiental implica colocar em jogo a subjetividade na produção de conhecimentos e traz consigo uma apropriação subjetiva do saber para ser aplicado em diferentes práticas e estratégias sociais, sendo movido pela pulsão de conhecimento, mas surge como um saber personalizado, definido por interesses, sentidos existenciais e significados culturais de sujeitos históricos (LEFF, 2001, p. 192-194).

Novos desafios no ensino, especialmente em nível de graduação e pósgraduação, apontam para a eminência de fatores que envolvam, não apenas as formações de profissionais/pesquisadores, mas, sobretudo, a formação humana continuada, numa dimensão para além da construção da racionalidade humana continuada, incluindo a dimensão da subjetividade da criatividade (BARRETO, 2007).

É importante perceber que a educação ambiental não é um processo mágico, e sim um processo contínuo de aprendizagem e exercício da cidadania e necessita de uma visão crítica da realidade e de uma atuação mais consciente no espaço social (NASCIMENTO, 2012).

Segundo Miola (2012), apesar de todos os avanços na educação ambiental no Brasil, ainda hoje ela continua sendo confundida com Ecologia e o entendimento dessa temática, no entanto, ainda é muito superficial em várias partes do país. Por vezes, as ações de Educação Ambiental restringem-se apenas a pequenas práticas de plantio de árvores e gerenciamento do lixo, deixando a desejar no que diz respeito aos objetivos e potencialidades desta ferramenta de educação popular. Segundo a autora, é preciso investimento em capacitação e formação de profissionais qualificados para que essa situação mude.

Muitos cursos voltados à gestão ambiental, já vem alterando sua ementa para disciplinas mais aplicadas. Como é o caso do curso de Gestão Ambiental do EAD-UNICESUMAR, onde a disciplina de educação ambiental articula o aluno não só, a saber, os históricos e fundamentos da disciplina, mas também, a saber, construir e aplicar projetos de educação ambiental tanto em escolas, quanto empresas e instituições em geral. Assim também acontece com o curso de Geografia da mesma instituição, que com a disciplina Recursos Naturais, Meio Ambiente e Desenvolvimento, proporciona ao aluno grande contato aos temas ambientais de grande relevância na atualidade, assim como mostra que 
através de práticas de educação ambiental e de desenvolvimento sustentável muitas melhorias ambientais são geradas, sendo estas técnicas oferecidas para o manejo e preservação dos ecossistemas. Ficando evidente a influência da práxis nestas disciplinas, tendo como objetivo apresentar, conceituar, distinguir e identificar aspectos e características relevantes sobre 0 tema Educação Ambiental, desenvolvendo o espírito crítico no aluno, visando uma postura consciente e proativa nas relações homem x natureza, rumo ao desenvolvimento sustentável.

Para Cunha (2013), os aportes metodológicos da pedagogia ambiental strictosensu muitas vezes circunscrevem-se meramente a técnicas que, numa visão externa, visam à conscientização e valorização dos ambientes, sem se preocupar com os sujeitos portadores de valores e conhecimentos próprios que secular ou milenarmente conservam a natureza para a reprodução da vida. Deve-se construir, nesse sentido, metodologias que levem em conta a lógica do outro em suas diferentes expressões a partir de sua relação histórica com seus territórios tradicionais, como ponto de partida fundamental para a construção de diálogo entre saberes.

Uma boa maneira de introduzir a educação ambiental no ensino superior é realizar uma analogia da paisagem com os alunos, levando-os a relatar como era os seus espaços de vivência na infância e como eles são hoje, assim teriam que identificar as mudanças ocorridas e problemáticas ocasionadas pelos processo de uso e ocupação do solo.

Nessa mesma abordagem pode-se levantar a questão das mudanças climáticas que vêm ocorrendo no planeta, as quais podem ser constatadas pelos nossos sensores sensitivos. Os microclimas são fortemente influenciáveis pela ação do homem, podendo citar como exemplo as "ilhas de calor" nos centros urbanos, que devido a intensa urbanização e a falta de áreas verdes acaba aumentando significativamente a temperatura destes ambientes, tendo o trabalho de campo com uma ótima ferramenta para esta observação. Desta forma, fica claro para o aluno que a apropriação do espaço pelo homem traz mudanças ambientais relevantes, sendo importante discutir as mudanças que os alunos detectam no ambiente, mais sempre partindo do local para o global.

Colaborando com tal argumentação, Cunha (2013), expõem que a pedagogia ambiental no campo da ação, não implica nem na transposição do ponto de vista do 
educador nem na consideração única e absoluta do ponto de vista do outro, mas a troca de saberes marcados por campos e sujeitos diferenciados. Ainda ressalta que a pedagogia ambiental realize metodologicamente a passagem do âmbito local para o global e vice-versa, considerando os processos atuais de globalização que afetam a dinâmica de cada lugar, o que leva a formações de identidades plurais ou transculturais.

Nesse sentido, é importante reconhecer que há diversos planos na atuação do educador ambiental ancorado na convivência dialética (e dialógica) da razão global e da razão local: um como "espaço movediço e inconstante formado por pontos, cuja existência funcional é dependente de fatores externos"; e outro "que se funda na ordem da cotidianidade, da co-presença, da vizinhança, da intimidade, da emoção, da cooperação e a socialização com base na contiguidade (SANTOS, 1997).

Para muitos especialistas, a educação ambiental se inicia na escola e posteriormente se espalha pela cidade, atingindo, em primeiro plano, a esfera local e, se for trabalhada de maneira diferenciada, possivelmente atingirá uma escala global (NASCIMENTO, 2012).

O trabalho voltado à educação ambiental busca ir além do cotidiano de cada cidadão, e uma luta frequente, onde se busca a mudança de hábito, este muitas vezes enraizado há décadas, contudo deve ser uma luta diária mostrando a necessidade de transformar os maus hábitos em bons.

A preocupação com o meio ambiente, associada às problemáticas ambientais de poluição, degradação do meio, crise dos recursos naturais nas diferentes escalas, tem questionado o papel do homem sobre o espaço e dessa forma exigiuse uma postura quanto às intervenções que favoreçam a proteção, ou melhor, uso do meio ambiente através das políticas públicas, fortalecendo sua proteção e sua sustentabilidade numa economia capitalista.

Repensar o meio ambiente exige além de estudo, uma postura política que exija das mais diferentes instituições uma mudança de atitude e uma maior preocupação com a natureza, dessa forma é necessário pensar em novas metodologias que possam unir preservação e uso sustentável, o que para Leff (2010, p. 62): “a crise ambiental problematiza os paradigmas estabelecidos do conhecimento e demanda novas metodologias capazes de orientar um processo de 
reconstrução do saber que permita realizar uma análise integrada da realidade", ou seja, conhecer sobre o que se pretende intervir.

Para tanto, no Brasil os problemas ambientais são muitos e alcançam escalas distintas desde desmatamento de uma área até o acumulo de resíduos sólidos sendo descartados no chão chegando aos rios, lagos e mares. Intervir sobre estes problemas é missão social, já que a sociedade acaba pagando caro por todas as intervenções ao meio ambiente.

Desde os primeiros anos em contato com a educação formal, os professores devem apresentar aos alunos como deve ser seu comportamento frente ao meio ambiente, e os cuidados que este desprende para qualidade de vida de toda a população. Apresentar cuidados simples como com o lixo, destinando este ao seu devido recipiente, fazendo-se uso da reciclagem, e não deixando lixo em qualquer lugar, como no caso do chão da sala de aula são atitudes que devem ser realizadas cotidianamente de uma forma natural. Mas para haver uma mudança de hábito é necessário relembrar e cobrar posturas diferentes todos os dias, já que nem todos tem conhecimento sobre a necessidade de cuidar do espaço em que se encontra, portando devemos educar as crianças para que tornem adultos responsáveis com o meio ambiente, ou que sejam pais que saibam repassar esses preceitos para seus filhos e familiares.

De acordo com Capra (1990), o estabelecimento de comunidades saudáveis e inteligentes não só é necessário para a sustentabilidade ecológica, como também facilita a aprendizagem. Alguns educadores acreditam que, idealmente, as escolas devem ser comunidades de aprendizes, onde experiências e desafios intelectuais sejam realmente vivenciados e não apenas verbalizados.

$\mathrm{Na}$ universidade, a busca por um trabalho integrado e interdisciplinar é o que orienta o estudo sobre o meio ambiente, já que em muitos casos não se tem uma disciplina específica, porém é um tema atual e necessário. De acordo com Leff (2010, p. 165) a "interdisciplinaridade proposta pelo saber ambiental implica a integração de processos naturais e sociais de diferentes ordens de materialidade e esferas de racionalidade", potencializando o olhar integrador dos aspectos socioambientais. 
Segundo Leff (2010, p. 174):

\begin{abstract}
O processo interdisciplinar mobiliza a produção de novos conhecimentos enquanto reste às disciplinas particulares um potencial a desenvolver em seu intercâmbio com outros saberes para compreender e resolver problemas sociais de nosso tempo; enquanto os sujeitos do saber conservarem um impulso por conhecer o desconhecido, a necessidade de descobrir e construir um mundo além do restrito horizonte de visibilidade da realidade e dos fatos; enquanto existir uma capacidade para conjecturar o que não é dedutível a partir da análise do dado, enquanto a necessidade emancipatória do ser humano não levar à construção de novas utopias e à exploração de alternativas além das opções oferecidas pelos referenciais teóricos herdados pela tradição do pensamento metafísico e do método científico, enquanto continuar viva a pulsação pelo saber, o pensamento crítico e o movimento criador das ideias.
\end{abstract}

De acordo com os apontamentos, o que precisamos é pensar e repensar cotidianamente nosso papel no espaço geográfico criando e recriando formas e meios para que o ensino-aprendizagem aconteça de maneira constante e criativa, através das mais diferentes ciências, mas unidas com um objetivo comum, a preservação e conservação do meio ambiente. Só assim será possível potencializar a sustentabilidade através do intercâmbio entre o saber e prática.

\title{
4. CONSIDERAÇÕES FINAIS
}

Ao trabalhar com a disciplina de educação ambiental e outras vinculadas a meio ambiente, foi possível observar a participação dos alunos através do encantamento com estas, e assim com o passar do tempo reconhecer o quanto é gratificante ver neles um crescimento no seu modo de ser e de agir em sala de aula. Identificou-se que hábitos questionáveis foram mudando aos poucos, e preocupações por parte dos alunos foram surgindo com relação ao futuro do planeta.

Ao trabalhar com educação ambiental e disciplinas da área de meio ambiente, busca-se através do conteúdo ser o mais claro possível, e mostrar a importância de reconhecer da natureza, fonte de recursos e de qualidade de vida que se tem quando o ambiente está em equilíbrio. Observou-se que gestos antes realizados de maneira impensada, hoje passam a ser observados e reavaliados considerando uma retomada quanto o modo de agir e atuar sobre o espaço que ocupamos. 
Os conteúdos trabalhados, dentre eles a interferência do homem no espaço geográfico, as fragilidades do meio ambiente e dos recursos naturais, os princípios e objetivos da educação ambiental, estratégias de aplicação da educação ambiental e sustentabilidade em escolas, empresas e na sociedade como um todo, além de seus desafios e perspectivas, potencializam essa forma de pensar e agir sobre a natureza, considerando seu papel enquanto agente modificador do espaço, observando a importância da disciplina mesmo que no ensino superior, conseguindo ser capaz de tocar pessoas para reavaliar seu comportamento antes considerado impensado, para uma atitude pensada e responsável.

A docência da disciplina de educação ambiental e com as diversas disciplinas das áreas ambientais que dão maior ênfase às questões ambientais, só terão bons resultados se o processo de ensino e aprendizagem nortear-se através da teoria e da prática, reiterando a importância e relevância dos conteúdos na formação da consciência ecológica dos alunos.

Dessa forma os alunos, ao analisarem estudos de caso e do meio, efetivarem atividades práticas, como criação de projetos de revitalização ou conscientização ambiental e atividades técnicas ou de campo, estarão se inteirando na temática ambiental, sendo muito mais fácil absorverem novos hábitos, pois sentirão necessidade em mudar suas posturas, diante de tantas problemáticas observadas no meio ambiente, onde a maioria foi desencadeada pelo homem, e com isso o seu lado preservacionista pode vim a aflorar diante da realidade em que se encontram.

Averiguamos que no decorrer da aplicação da práxis no ensino aprendizagem no ensino superior houve mudanças significativas na postura da maior parte dos alunos, o que ressalta a importância da disciplina educação ambiental, promovendo uma linguagem única em torno da proteção e defesa ambiental.

No entanto, a crítica que deixamos é pela falta da disciplina de educação ambiental nas grades curriculares de muitos cursos ou pela sua abordagem inexistente, fato que acaba prejudicando o seu eficaz processo de difusão. Portanto deve-se haver uma discussão entre os docentes sobre sua importância e sua inclusão dentro dos cursos, nem que seja de forma especial, sobretudo nos cursos de licenciatura e nos vinculados a área ambiental, os quais carecem de conhecimento mais sólidos sobre a temática, para poderem aplicá-la não só como 
cidadãos, mas também poderem repassar o conhecimento adquirido em suas vidas profissionais.

O Programa Nacional de educação ambiental (ProNEA, 2005), oferece vários incentivos à implementação de estudos, pesquisas e experimentos em educação ambiental, entre eles, oferece apoio aos projetos de pesquisa voltados à construção de instrumentos, metodologias e processos para a abordagem da dimensão ambiental, que possam inclusive ser incorporados aos currículos integrados dos diferentes níveis e modalidades de ensino, sendo este então mais um incentivo às instituições de ensino superior, a incorporarem a Educação Ambiental em suas grades curriculares.

\section{REFERÊNCIAS}

ATOS DO PODER LEGISLATIVO - LEI № 9.795, de 27 de abril de 1999.

BARRETO, MARIBEL OLIVEIRA. O papel da criatividade no ensino superior. Revista Diálogos e Ciência. Ano v., n 12, dez. 2007.

BUARQUE, CRISTOVAM. A desordem do progresso: o fim da era dos economistas e a construção do futuro. Rio de Janeiro: Paz e Terra, 1990.

CAPRA, FRITJOF. Alfabetização ecológica: o desafio para a educação do século 21. Nosso, futuro comum - o Relatório Brundtland. Editora da Fundação Getúlio Vargas. Rio de Janeiro, 1990.

CARNEIRO, SÔNIA MARIA MARCHIORATO. Fundamentos epistemo-metodológicos da educação ambiental. Educar. Editora UFPR, n. 27, Curitiba, 2006, p. 17-35.

CUNHA, LUCIA HELENA DE OLIVEIRA. Diálogo de Saberes na Pedagogia Ambiental. Disponível em: http://www.pnuma.org/educamb/documentos/Dialogo_saberes.pdf acessado em 05/08/14

UNESCO. Carta de Belgrado. lugoslávia, 1975.

GADOTTI, MOACIR. Pedagogia da práxis e educação ambiental. Ministério do Meio Ambiente Diretoria de Educação Ambiental. Programa de Formação de Educadoras e Educadores Ambientais. Disponível em: http://siteantigo.paulofreire.org/pub/Institu/Sublnstitucional1203023491/t003Ps002/Ped_praxis_educa cao_ambiental_2005.pdf Acessado em: 04/08/14

GLEISER, MARCELO. A dança do universo: dos mitos da criação ao big bang. São Paulo, Companhia das letras, 1997.

LEFF, ENRIQUE. Saber Ambiental. Petrópolis-RJ: Vozes, 2001.

LEFF, ENRIQUE. Epistemologia Ambiental. 5 ed. São Paulo: Cortez, 2010.

MIKHAILOVA, IRINA. Sustentabilidade: evolução dos conceitos teóricos e os problemas da mensuração prática. Revista Economia e Desenvolvimento, n 16, Santa Maria, 2004.

MARTINS, JOAQUIM JUNIOR. Como Escrever Trabalhos de Conclusões de Cursos. $4^{\circ}$ ed; Rio de janeiro, Editora Vozes, 2008. 
MIOLA, DEISE TATIANE BUENO. O surgimento da Educação Ambiental. Disponível em: http://www.grnews.com.br/18052012/deisemiola/o-surgimento-da-educacao ambiental?option=com_content\&view=article\&id=16605\&Itemid=174 acessado em 04/08/14.

NASCIMENTO, PATRICIA BRANCO do. Educação Ambiental. Gestão Ambiental. Núcleo de Educação a Distância. Centro Universitário de Maringá. Maringá-PR, 2012.

PROGRAMA NACIONAL DE EDUCAÇÃO AMBIENTAL - ProNEA / Ministério do Meio Ambiente, Diretoria de Educação Ambiental; Ministério da Educação. Coordenação Geral de Educação Ambiental. - 3. ed - Brasília : Ministério do Meio Ambiente, 2005, 102p.

SANTOS, MILTON. O. O espaço: sistema de objetos, sistemas de ação. In: A Natureza do Espaço. São Paulo: Hucitec, 1997 (2ª̣edição).

SILVA, JOSÉ AFONSO da. Direito ambiental constitucional. 5. ed. São Paulo: Malheiros, 2004. TROPPMAIR, HELMULT. Biogeografia e Meio Ambiente. 5 ed. Rio Claro: Divisa, 2002. 